\title{
COTA PARA CANDIDATURAS FEMININAS: UMA ANÁLISE DO ACÓRDÃO TRESC N. 33.172, DE 13.8.2018, À LUZ DA AÇÃO AFIRMATIVA DE INCLUSÃO DE GÊNERO
}

\author{
Hugo Frederico Vieira Neves
}

Resumo: As mulheres, no Brasil, somam mais da metade dos eleitores regularmente inscritos e alistados perante a Justiça Eleitoral ${ }^{1}$. Não obstante, a tradição política brasileira, desde há muito, tem acentuado viés de predominância masculina, resguardando aos homens, portanto, a ocupação dos cargos eletivos de representatividade nas unidades da Federação. Em alguma medida, isto se deve ao reconhecimento tardio da capacidade eleitoral ativa das mulheres - mais especificamente, o direito de votar -, ocorrido, ainda que parcialmente e com restrições, apenas a partir de 1932, por meio do Decreto n. 21.076 ${ }^{2}$, do então Presidente (e ditador) Getúlio Vargas, chegando à sua plenitude a partir de 1946, quando então foi instituída a obrigatoriedade do voto feminino. O movimento social pelo sufrágio das mulheres desembarcou com atraso no Brasil. A luta pela conquista da cidadania plena das mulheres tem suas origens no final do século XIX, quando a Nova Zelândia foi o primeiro país a garantir este direito, logo se estendendo pelo Velho Continente ${ }^{3}$. E aqui fica o convite para que o leitor assista o filme "As sufragistas", que narra a história de um grupo de mulheres britânicas que lutou pelo direito ao voto no início do século XX. Assim, no Brasil, apenas algumas décadas nos separam de uma época obscura em que as mulheres eram consideradas cidadãs de segunda classe, haja vista a restrição de seus direitos político-constitucionais. Nada obstante, tal como vem ocorrendo nas democracias contemporâneas, o país passou a vivenciar, nos últimos anos, a intensificação dos debates públicos sobre a participação política das mulheres nos parlamentos, fazendo surgir no cenário legislativo a ação afirmativa de reserva de cotas para candidaturas, o que ocorreu por meio da Lei n. 9.504/1997. Embora a eficácia plena da norma eleitoral que impõe a ação afirmativa da cota de gênero para candidaturas ainda encontre alguma resistência nas Cortes de Justiça Eleitoral, o Tribunal Regional Eleitoral de Santa Catarina, enfrentando esta questão, julgou de forma inédita, caso em que restou configurada a fraude no atendimento do requisito normativo. Como consequência, decidiu-se pela cassação do registro de todos os candidatos (homens e mulheres) dos partidos envolvidos e, consequentemente, dos votos recebidos e mandatos conquistados. A decisão não está isenta de críticas, porquanto produz, fora do pleito eleitoral e longe daqueles que tem o poder de decisão - os eleitores -, indesejável rearranjo dos resultados sufragados nas urnas. Assim, poder-se-ía dizer que o Tribunal Eleitoral incorreu em manifesto ativismo judicial, suplantando-se sobre as agremiações partidárias e os eleitores? Ou será que a ação mais enérgica da Justiça Eleitoral, que opera como Guardiã das Eleições, visa justamente conferir maior eficácia à norma que introduziu a ação afirmativa de participação efetiva das mulheres na política? Lançar luzes nestes questionamentos é o que se espera no presente artigo, de estudo do precedente lavrado no Acórdão n. 33.173, de 13.8.2018, com ênfase nos votos que compuseram a maioria divergente.

Palavras-chave: Representatividade feminina. Participação política. Ação afirmativa. Eficácia jurisdicional.

\footnotetext{
${ }^{1}$ http://www.tse.jus.br/eleitor/estatisticas-de-eleitorado/eleitorado. Acesso em 12 ago. 2019.

285 anos do voto feminino no Brasil. Procuradoria Regional Eleitoral de São Paulo. http://www. presp.mpf.mp.br/index.php/area-juridica/publicacoes/blog-presp/1938-85-anos-do-voto-feminino-no-brasil. Acesso em 10 ago. 2019.

${ }^{3}$ Idem.
} 


\section{Breve introdução}

A Lei n. 9.504/1997, ao estabelecer regras gerais para as eleições, trouxe em seu corpo normativo a disposição sobre percentuais mínimos e máximos de cada sexo ${ }^{4}$ que devem ser observados pelos partidos e coligações partidárias.

Este condicionamento está enunciado no art. 10, \ 3으, do mencionado diploma legal, que possui esta redação:

Art. 10. Cada partido ou coligação poderá registrar candidatos para a Câmara dos Deputados, a Câmara Legislativa, as Assembleias Legislativas e as Câmaras Municipais no total de até 150\% (cento e cinquenta por cento) do número de lugares a preencher, salvo:

(...)

\3ํㅡo número de vagas resultante das regras previstas neste artigo, cada partido ou coligação preencherá o mínimo de 30\% (trinta por cento) e o máximo de $70 \%$ (setenta por cento) para candidaturas de cada sexo.

Efetivamente, conforme se extrai da regra, não se trata de reservar $30 \%$ das vagas resultantes do cálculo do art. 10 exclusivamente para as candidaturas femininas. Em outras palavras, quaisquer dos sexos pode figurar no percentual mínimo ou no patamar máximo, devendo as candidaturas do sexo oposto observarem igual regência em sentido contrário.

Todavia, sabe-se pela prática e até em razão da própria tradição histórica narrada no introito deste artigo, que as candidaturas femininas, quando muito, são alocadas irremediavelmente no patamar mínimo de $30 \%$, jamais pelo máximo de $70 \%$, o que seria igualmente permitido.

Nada obstante, é importante salientar, desde logo, que a redação originária do parágrafo terceiro continha a expressão verbal "deverá preencher" no lugar de "preencherá".

A alteração não surgiu à toa; após inúmeros casos judicializados sobre fraude na composição das cotas de sexo, o legislador ordinário percebeu que a locução verbal permitia interpretações mais elásticas sobre a obrigatoriedade da norma, de tal forma que houve por bem alterar a redação do mencionado dispositivo.

\footnotetext{
${ }^{4}$ GOMES, José Jairo. Direito Eleitoral. 14. ed. rev., atual. e ampl. São Paulo: Atlas, 2018.
} 
Com efeito, o objetivo do legislador era claro: impor aos partidos e coligações a apresentação compulsória de candidatos de ambos os sexos para os pleitos, permitindo maior paridade de armas na representatividade entre homens e mulheres.

Em verdade, trata-se de manifesta política afirmativa, opção feita pelos congressistas da década de 90 em face das pressões sociais que havia em muitos países democráticos.

Hoje, a regra já é considerada um marco no avanço civilizatório de igualdade de gêneros, sendo que o debate já evoluiu para a criação de leis que imponham cotas nas cadeiras dos parlamentos.

Outra questão relevante que circunda o tema da participação feminina na política diz respeito à ausência de democracia no seio das agremiações partidárias, mas isto demandaria outro artigo específico sobre o tema.

Por fim, cabe destacar que o conceito da fraude, para fins de cabimento de Ação de Impugnação de Mandato Eletivo, prevista no art. 14, \10, da Constituição Federal, é aberto, sendo possível considerar todas as hipóteses em que a normalidade das eleições e a legitimidade do mandato eletivo são afetadas por ações fraudulentas ${ }^{5}$, inclusive nos casos de fraude à lei.

\section{Análisejurisprudencialsobre orequisito de preenchimento das candidaturas com reserva de vaga de sexo}

Enfrentando a matéria, o Tribunal Regional Eleitoral de Santa Catarina, por meio do Acórdão n. 33.172, de 13/8/2018, da lavra do Juiz Wilson Pereira Júnior ${ }^{6}$, se posicionou reconhecendo a ocorrência de fraude em Ação de Impugnação de Mandato Eletivo originária do Município de Sombrio, julgada improcedente na primeira instância.

Os contornos do exame recursal dizem respeito a 4 (quatro) registros de candidaturas femininas, ao cargo de vereador do Município de Sombrio, foram levados a efeito apenas para que a Coligação PMDB-PSB-PRB-DEM atendesse aos coeficientes de sexo previstos no art. 10, $\int 3^{\circ}$, da Lei n. 9.504/1997.

\footnotetext{
${ }^{5}$ ZILIO, Rodrigo López. Direito Eleitoral. 3. ed. Porto Alegre: Verbo Jurídico, 2012.

${ }^{6}$ Acórdão TRESC n. 33.173 de 13/8/2018, Relator o Juiz WILSON PEREIRA JÚNIOR, Publicação: DJE - Diário de JE, tomo 144, Data 21/8/2018, págs. 19-20.
} 
Argumentava-se que houve fraude, nos termos do art. 14, $\int 10$, da Constituição Federal, no que diz respeito às candidaturas femininas de quatro candidatas ao cargo de vereador que, segundo os recorrentes, haviam sido registradas tão somente para que a coligação partidária pudesse atender aos percentuais estabelecidos no art. 10, \3으 da Lei n. 9.504/1997.

Aduziu-se, neste contexto, que os resultados eleitorais ínfimos obtidos, as renúncias que antecederam o pleito e a prestação de contas das candidatas mulheres caracterizavam a fraude perpetrada.

A ação foi julgada improcedente na primeira instância e, em grau de recurso, o TRESC, por maioria, assim se pronunciou na ementa deste julgado:

\section{EMENTA DO VOTO VENCEDOR:}

- ELEIÇÕES 2016 - RECURSO ELEITORAL - AÇÃO DE IMPUGNAÇÃO DE MANDATO ELETIVO - ART. 14, 』 10 DA CONSTITUIÇÃO FEDERAL.

- PRELIMINARES AFASTADAS PELA CORTE, À UNANIMIDADE. - MÉRITO: LANÇAMENTO DE CANDIDATURAS FEMININAS FICTÍCIAS PARA ATENDIMENTO DO PERCENTUAL FIXADO PARA A COTA DE GÊNERO - FRAUDE NO PREENCHIMENTO DA COTA MÍNIMA PREVISTA NO ART. 10, $\int 3^{\circ}$, DA LEI N. 9.504/1997 - EXISTÊNCIA DE PROVAS SUFICIENTES DA FRAUDE: BAIXÍSSIMA VOTAÇÃO OBTIDA POR QUATRO CANDIDATAS, UMA DELAS COM VOTAÇÃO ZERADA; COMPROVAÇÃO DE QUE A CANDIDATA QUE RECEBEU APENAS UM VOTO, SEQUER VOTOU NELA MESMA; CANDIDATA QUE VIAJOU AO EXTERIOR EM PLENA CAMPANHA ELEITORAL E LÁ PERMANECEU POR 12 (DOZE) DIAS; MOVIMENTAÇÃO FINANCEIRA ÍNFIMA NA CAMPANHA DAS CANDIDATAS, BASICAMENTE RELATIVA À DOAÇÃO ESTIMÁVEL EM DINHEIRO DE SERVIÇOS ADVOCATÍCIOS E CONTÁBEIS; DEPOIMENTOS PESSOAIS REVELADORES DA AUSÊNCIA DE PARTICIPAÇÃO EFETIVA DAS CANDIDATAS MULHERES NO PLEITO ELEITORAL - CASSAÇÃO DOS MANDATOS OBTIDOS PELA COLIGAÇÃO PARA A ELEIÇÃO PROPORCIONAL, PARA O CARGO DE VEREADOR, POR TEREM SIDO OBTIDOS MEDIANTE FRAUDE NA ORIGEM DA COLIGAÇÃO - NULIDADE DE TODOS OS VOTOS ATRIBUÍDOS À CO- 
LIGAÇÃO NA ELEIÇÃO PROPORCIONAL DE 2016, COM A DISTRIBUIÇÃO DOS MANDATOS DE VEREADOR POR ELA CONQUISTADOS, NOS TERMOS DO ART. 109 DO CÓDIGO ELEITORAL, AOS DEMAIS PARTIDOS OU COLIGAÇÕES QUE ALCANÇARAM O QUOCIENTE PARTIDÁRIO PROVIMENTO DO RECURSO.

\section{EMENTA DO VOTO VENCIDO:}

- ELEIÇÕES 2016 - RECURSO ELEITORAL - AÇÃO DE IMPUGNAÇÃO DE MANDATO ELETIVO.

- PRELIMINAR - ILEGITIMIDADE PASSIVA DOS CANDIDATOS NÃO ELEITOS OU NÃO DIPLOMADOS E INDEFERIMENTO DA INICIAL QUANTO A ESSES CANDIDATOS - ALEGAÇÃO DE QUE A INICIAL NÃO DESCREVE NENHUMA CONDUTA A ELES ATRIBUÍDA, NEM APONTA OS FUNDAMENTOS JURÍDICOS COM QUE SE PRETENDE REQUERER SUAS PUNIÇÕES - LITISCONSÓRCIO PASSIVO NECESSÁRIO - OBRIGATORIEDADE DE TODOS OS CANDIDATOS ELEITOS E SUPLENTES VINCULADOS AOS PEDIDOS DE REGISTRO COLETIVO ALEGADAMENTE FRAUDADOS INTEGRAREM O POLO PASSIVO DA DEMANDA - PRECEDENTES DO TRESC - REJEIÇÃO.

- PRELIMINAR - ILEGITIMIDADE PASSIVA DA COLIGAÇÃO - ALEGAÇÃO DE FRAUDE NA CONSTITUIÇÃO DE TODA A CHAPA PROPORCIONAL - CAUSA DE PEDIR QUE, SE ACOLHIDA, PODE DETERMINAR A DESCONSTITUIÇÃO DO DEMONSTRATIVO DE REGULARIDADE DE ATOS PARTIDÁRIOS (DRAP) DA COLIGAÇÃO, COM A CONSEQUENTE CASSAÇÃO DOS DIPLOMAS DE TODOS OS SEUS CANDIDATOS - LEGITIMIDADE PASSIVA RECONHECIDA - REJEIÇÃO.

- MÉRITO - ALEGAÇÃO DE LANÇAMENTO, PELA COLIGAÇÃO, DE CANDIDATURAS FEMININAS FICTÍCIAS FRAUDE NO PREENCHIMENTO DA COTA MÍNIMA POR GÊNERO - ART. 10, 』3, DA LEI N. 9.504/1997 - AUSÊNCIA DE COMPROVAÇÃO DA CONDUTA FRAUDULENTA CONDENAÇÃO QUE EXIGE A APRESENTAÇÃO DE PROVAS ROBUSTAS E INCONTROVERSAS - DESPROVIMENTO. 
O voto da Relatora (Juíza Luísa Hickel Gamba) a quem o recurso foi originariamente distribuído se pautou no sentido de rejeitar as preliminares e, no mérito, manter a sentença que julgou improcedente a ação, sob o argumento de que as circunstâncias do caso concreto não seriam suficientes para comprovar a fraude à norma eleitoral.

Inaugurada a divergência, portanto, quanto à matéria de fundo, foram pinçadas justamente as circunstâncias que, interpretadas conjuntamente, revelavam o ardil das candidaturas fictícias.

A coligação havia lançado para o cargo de vereador 22 (vinte e dois) candidatos. Destes, 15 (quinze) eram do sexo masculino e 7 (sete) do sexo feminino, o que se enquadrava com precisão matemática no cálculo de proporcionalidade determinado pelo $\int 3^{\circ}$ do art. 10 da Lei n. 9.504/1997.

Anotou-se que quatro das candidatas mulheres, que haviam originalmente pedido registro de candidatura para o cargo de vereadora, desistiram dias antes do prazo fatal, sendo substituídas por outras cujas candidaturas foram posteriormente impugnadas sob o argumento de fraude.

Neste contexto, observou-se que as candidaturas substitutas foram feitas tão somente para evitar que um dos candidatos do gênero masculino tivesse que ser excluído, pois os cálculos são feitos a partir do número de candidatos efetivamente registrados perante a Justiça Eleitoral.

Para tanto, observou-se, ainda, o número de votos atribuídos às candidatas, que receberam, respectivamente, 5 (cinco), 2 (dois), 1 (um) e 0 (zero!) votos, num contexto de 21.859 eleitores do município.

Outra evidência considerada como circunstância que se somou às demais para concluir pela orquestração de um esquema fraudulento foi o fato de uma das candidatas substitutas não ter votado em si mesma, conforme observado a partir do relatório de totalização, onde se descobriu que o único voto conquistado pela candidata ocorreu em local de votação diverso daquele em que ela estava registrada.

Não obstante, o que mais chamou a atenção da Corte catarinense foi o fato de uma das candidatas ter viajado para o exterior no início da campanha.

Neste caminhar, não escapou ao juízo do Tribunal a exiguidade do prazo da campanha para promoção das candidaturas, abreviado que foi legalmente para somente irromper na data de 15 de agosto (Lei n. 9.504/1997, 
art. 36), encurtando o lapso temporal entre o início da campana e a eleição realizada em outubro.

De fato, o sintético período de campanha é valioso para aqueles que realmente pretendem disputar um mandato eletivo, tempo que não pode ser desperdiçado em atividades que não tenham relação com a divulgação de propostas e da própria imagem do candidato.

Das prestações de contas das candidatas extraíram-se informações que se somaram ao conjunto de evidências. A arrecadação de recursos estimáveis em dinheiro, ainda que de pouca monta, não foi acompanhada por gastos de campanha, que se mostraram inexistentes.

Finalmente, um último fato compôs o acervo de circunstâncias a revelar o ardil: a candidata que rumou para o exterior no início da campanha era cônjuge do presidente do partido ao qual estava filiada, sendo que este fez manifesta campanha para outro candidato do sexo masculino, inclusive por meio de publicações em redes sociais.

Cediço que cada fato tomado isoladamente não seria suficiente para a comprovação da fraude perpetrada.

Todavia, ao somarem-se e articularem-se mutuamente, evidenciaram manifesto propósito de burlar a lei, revelando o pouco apreço de seus integrantes pela política afirmativa estabelecida pelo Congresso Nacional.

Efetivamente, diante das circunstâncias do caso concreto antes narradas e da incompreensão política manifestada pelas candidatas em seus depoimentos judiciais, desvelaram-se candidaturas forjadas, meramente protocolares, requeridas com o único intento de compor a cota mínima de sexo, a autorizar o deferimento do Demonstrativo de Regularidade de Atos Partidários (DRAP), processo que, conferindo regularidade e legalidade ao partido/coligação, antecede o julgamento dos registros de candidaturas e sem o qual estes não podem ser apreciados.

A falsidade comprovada afetou, na origem, o DRAP, levando, assim, à revogação do deferimento de todas as candidaturas da chapa proporcional, cassando os mandatos obtidos pela coligação, na eleição proporcional, para o cargo de vereador (titular ou suplente), e declarando nulos os votos a ela atribuídos, o que levou à retotalização das eleições. 


\section{Considerações finais}

No precedente sob análise, verificou-se que a existência de votações pífias percebidas por candidatas mulheres é indicativo de que a política afirmativa feminina, ainda que tenha sido positivada, muito carece de ser reafirmada pela Justiça Eleitoral.

Logo, afastam-se as suposições de existência de ativismo judicial. Não é disso que se trata. Ao revés, a plena eficácia da norma exige interpretação restritiva, a fim de garantir maior equidade na esfera da representação política entre homens e mulheres.

A sub-representação feminina nos parlamentos de todas as esferas - federal, estadual e municipal - impede que políticas públicas de temas relevantes como saúde, segurança e educação, tenham visões distintas, para muito além do ideário masculino que permeia essas questões na sociedade brasileira.

Desta forma, a representação das mulheres na política se revela fundamental para que possam continuar atuando como protagonistas de suas lutas, assim como para equilibrar os espaços nas relações de poder.

Com efeito, o precedente destacado revela que o Tribunal Regional Eleitoral de Santa Catarina - sem desconsiderar a premissa de que o resultado soberano das urnas deve prevalecer - não permitiu que a Democracia fosse vitimada pela burla à lei eleitoral, sobretudo num assunto tão caro à sociedade como é a participação das mulheres na vida política nacional.

Fundamental reconhecer, por fim, que a Corte catarinense, ao se posicionar desta forma, consignou que fraudes desta espécie não maculam apenas o processo eleitoral de um determinado pleito, mas, sobretudo, depõem contra a luta histórica travada nas últimas décadas pelo reconhecimento da cidadania plena das mulheres e por seu justo espaço na política.

Afinal, lugar de mulher é onde ela quiser! 


\section{Referências}

85 anos do voto feminino no Brasil. Procuradoria Regional Eleitoral de São Paulo. http://www.presp.mpf.mp.br/index.php/area-juridica/publicacoes/ blog-presp/1938-85-anos-do-voto-feminino-no-brasil. Acesso em 10 ago. 2019.

Sítio do Tribunal Superior Eleitoral: http://www.tse.jus.br/eleitor/estatisticas-de-eleitorado/eleitorado. Acesso em 12 ago. 2019.

GOMES, José Jairo. Direito Eleitoral. 14. ed. rev., atual. e ampl. São Paulo: Atlas, 2018.

ZILIO, Rodrigo López. Direito Eleitoral. 3. ed. Porto Alegre: Verbo Jurídico, 2012.

Hugo Frederico Vieira Neves - Servidor público efetivo do Quadro Permanente do Tribunal Regional Eleitoral de Santa Catarina, Assessor Jurídico dos Juízes do Pleno. Bacharel em Direito pela Universidade do Vale do Itajaí. Licenciado em Letras pela Universidade Federal de Santa Catarina. Pós-graduado em Direito do Estado pela Universidade Anhanguera. Professor autônomo de Direito Eleitoral na Pós-graduação da Universidade do Vale do Itajaí. Palestrante e conferencista de Direito Eleitoral. Foi Vice-Diretor da Escola Judiciária Eleitoral de Santa Catarina e atualmente é Membro Efetivo do Instituto dos Advogados de Santa Catarina. 
